\title{
Coda- $Q$ Before and After the 1986 Andreanof Islands Earthquake
}

\author{
Zhong-Xian Huang ${ }^{1,2}$ and CARL Kisslinger ${ }^{1}$
}

\begin{abstract}
Coda- $Q$ values before and after the May 7, 1986 Andreanof Islands earthquake in the central Aleutian subduction zone were calculated from microearthquake seismograms on the basis of Aki's single backscattering model. Digital waveforms from 329 microearthquakes in 5.4 years before the mainshock and 40 aftershocks recorded by 11 stations of the Central Aleutians Seismic Network were utilized. Before the mainshock, coda- $Q$ in the rupture zone west of the mainshock epicenter was $15 \%$ higher than the $Q$ outside the rupture zone to the west. A low $Q$ in the region east of the mainshock epicenter is inferred, but lacks solid evidence. The high $Q$ region accords with the part of the rupture zone where most seismic moment was released. During approximately two months after the mainshock, coda- $Q$ in the rupture zone decreased about $10 \%$. Precursory $Q$ changes were not found in the 5.4 years before the mainshock. It is deduced that a coda- $Q$ precursor, if it existed, was of small magnitude $(<10 \%)$, or its duration was either shorter than one year or longer than four years.
\end{abstract}

Key words: Coda- $Q$, subduction earthquakes, Aleutian Islands.

\section{Introduction}

High-frequency coda waves from local earthquakes have been frequently used to study attenuation and heterogeneity in the lithosphere. Since the scattering and attenuation of high frequency waves are affected by stress- and fluid-related processes in the crust, it is reasonable to hypothesize that coda- $Q$ in an earthquake source region may vary with time during the preparation for and occurrence of an earthquake (AKI, 1985). Several authors have reported precursory coda- $Q$ changes before some large earthquakes. GuSEV and LEMZIKOV (1985) found that the coda shape changed during one year before each of three Kurile-Kamchatka earthquakes (about magnitude 8), and returned to normal after the mainshock. The anomaly magnitude is equivalent to a coda- $Q$ decrease of about $20 \%$. JIN and AKI (1986) reported a very large coda- $Q$ change before the 1976 Tangshan, China earthquake. SATO (1988) published a comprehensive list of references on the subject.

Other studies of earthquake-related coda- $Q$ variations were published by TsukudA (1988), HuANG and Wyss (1988), and Su and AKI (1990). These

\footnotetext{
${ }^{1}$ Cooperative Institute for Research in Environmental Science and Department of Geological Sciences, Campus Box 216, University of Colorado, Boulder, CO 80309, U.S.A.

${ }^{2}$ Now at: Institute of Crustal Dynamics, P.O. Box 2855, Beijing, China 100085.
} 
authors studied coda- $Q$ change associated with moderate earthquakes (about magnitude 6). Digital data recorded at short epicentral distances were used, so that relatively good spatial resolution could be achieved. The pre-mainshock temporal variations of coda- $Q$ reported in these three papers are basically different from each other. SU and AKI (1990) reported that in the source region coda- $Q$ decreased then increased again before the mainshock, most prominently in the $12 \mathrm{~Hz}$ frequency band. According to TsUKUDA (1988), coda- $Q$ varied sinusoidally, with a peak preceding the mainshock in the 5 and $10 \mathrm{~Hz}$ bands. HUANG and WYSS (1988) showed that coda- $Q$ below $15 \mathrm{~Hz}$ was remarkably stable before the 1983 Hawaii earthquake, although at higher frequencies a slight $Q$ decrease $(5-10 \%)$ was detected which, in their opinion, could not be reliably identified as a precursor.

On the other hand, coda- $Q$ studies so far do show some relatively consistent features related to earthquakes. First, coda- $Q$ differences between the pre- and post-mainshock stages were found by all studies when data were available (JIN and AKI, 1986; GuSEV and LeMzIKov, 1985; PeNG et al., 1987; Novelo-CASANOVA et al., 1985; TSUKUDA, 1988; SU and AKI, 1990). In this paper we use "coseismic" change to refer to the difference derived from pre-shocks and early aftershocks. Secondly, spatial differences in coda- $Q$ have been detected between the mainshock source region and the surrounding area (PENG et al., 1987; SU and AKI, 1990) or among different parts of the source region (Novelo-CASANOVA et al., 1985; HUANG and WYss, 1988). PENG et al. (1987) also reported that the spatial difference that existed before the mainshock disappeared after the earthquake, indicating that the spatial difference could be caused by the earthquake preparation process. The magnitude of the coseismic change is generally in the $20-30 \%$ range, but both $Q$ increases and decreases were found.

In searching for observational evidence of earthquake-related variations, the absolute $Q$ value is not important, as long as there is a relation between coda decay rate and the attenuation in the medium. In this paper we report the temporal and spatial distribution of coda- $Q$ in the central Aleutian subduction zone where a major earthquake $\left(M_{s}=7.7\right)$ took place in 1986 . Abundant high quality digital data recorded by the Central Aleutian Seismic Network (CASN) are available since January, 1981. The study area includes the major part of the mainshock rupture zone (ENGDAHL et al., 1989), mostly west of the epicenter, and a region west of the rupture zone. The spatial and temporal distributions of $Q$, before and immediately after the mainshock, are presented and some interpretation of the results offered.

\section{The Mainshock and the Tectonic Setting}

The epicenter of the May 7, 1986 Andreanof Islands earthquake was located at $51.33^{\circ} \mathrm{N}, 174^{\circ} \mathrm{W}$, at a constrained focal depth of $25 \mathrm{~km}$ (ENGDAHL et al., 1989). The magnitude was $M_{s}=7.7$ or $M_{w}=8.0$ (HWANG and Kanamori, 1986). This 


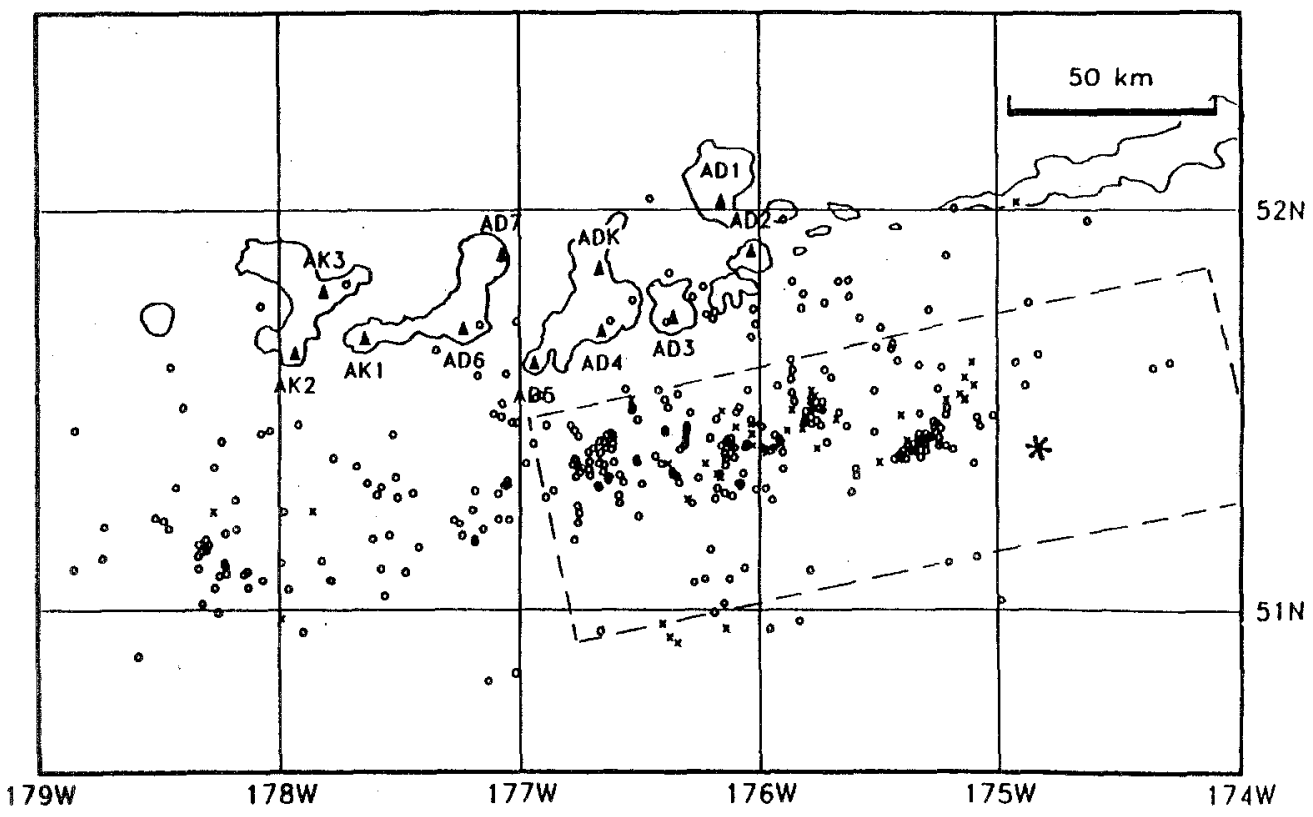

Figure 1

Map of the part of the central Aleutians seismic zone monitored by the CASN. Asterisk marks the epicenter of the 1986 Andreanof Islands earthquake. Dashed rectangle shows the approximate one-day aftershock zone. Solid triangles are stations. Circles are preshocks; crosses are aftershocks.

earthquake ruptured a $240 \mathrm{~km}$ segment along the central Aleutian subduction zone (Figure 1). Figure 1 also shows the stations of the CASN and the epicenters of the microearthquake used in this study. The regional tectonics are described in detail in ENGDAHL et al. (1989).

The entire central Aleutian arc was ruptured in the great March 9, 1957 earthquake. The epicenter was located near $51.3^{\circ} \mathrm{N}$ and $175.8^{\circ} \mathrm{W}$, about $70 \mathrm{~km}$ west of the 1986 epicenter (ENGDAHL et al., 1989). Since the aftershocks of the 1957 event, only one thrust-zone earthquake with magnitude above 7 took place, in May 1971 , at $51.22^{\circ} \mathrm{N}, 177.12^{\circ} \mathrm{W}$ beneath Adak Canyon (LAFORGE and ENGDAHL, 1979). The western boundary of the aftershock zone of the 1986 event is near the eastern edge of Adak Canyon (approximately $177^{\circ} \mathrm{W}$ ).

Several studies of the source characteristics of the 1986 mainshock have been conducted (Hwang and KANAMORI, 1986; Boyd and NABELEK, 1988; Houston and ENGDAHL, 1989; DAS and Kostrov, 1990). The focal mechanism determined by first motions and waveform inversion was consistent with the plate convergence in this region. The largest moment release occurred in a fault segment west of the epicenter, near the epicentral area of the great 1957 earthquake and within the part of the seismic zone that is monitored well by the CASN. 


\section{Data and Method of Analysis}

The CASN has produced digital seismic recordings since January, 1981. Analog signals are recorded on magnetic tapes, then digitized at a sampling rate of 75 samples per second. The recording length for each event is about two minutes. The network consists of 14 stations. In this study the horizontal-component recordings from 11 stations were used. Among them the stations AD1, AD2, AD3, AD4, AD5, ADK, and AK1 (Figure 1) contributed generally continuous recordings from January, 1981 through July, 1986, the end of the data used here. Station AD6 contributed from 1982 to 1984. Station AK2 and AK3 provided data in 1981 only. For the aftershock study only stations AD1, AD2, AD3, and ADK were used.

All seismograms were plotted and inspected before processing. Those with low signal-to-noise ratio, saturated within the analysis window, or suspected to be multiple events were discarded. In the time period from January, 1981 to April, 1986, 329 earthquakes were selected for the coda- $Q$ study. About 1000 total data points (source-receiver pairs) resulted. We picked some 40 aftershocks that occurred between June 24 and August 1, 1986 for the study.

Coda- $Q$ was calculated from the coda decay rate according to Aki's single backscattering model (AKI and CHOUET, 1975). The coda amplitude $A(f \mid t)$ can be written as $A(f \mid t)=C(f) t^{-1} \exp (-\pi f t / Q)$ where $f$ is frequency, $t$ is travel time, $C(f)$ is the source term. Sixty seconds of the digital data, starting from one half second after the $S$-wave arrival, were passed through a zero-phase-shift band-pass filter. The center frequencies for the four bands were $1.5,3,6,12 \mathrm{~Hz}$, with band width of $1,2,3,8 \mathrm{~Hz}$, respectively. The rms amplitudes were calculated for each consecutive two-second interval. After subtracting the back-ground noise energy measured in a ten-second window before the $P$-wave arrival, the amplitudes were corrected for geometrical spreading of body waves. Least squares linear regression was used to determine the decay slope, $b$, and its standard error, $d b$. Coda- $Q$ and the relative standard error $d Q / Q$ were calculated from $Q=\pi f / b$, and $d Q / Q=$ $-d b / b$.

Coda- $Q$ values were measured in two different time windows corresponding to different sizes of the volume sampled by coda waves. Window 1 began at 6.5 seconds after the $S$ arrival and was 24 seconds long. Window 2 began at 12.5 seconds after the $S$ arrival and was 48 seconds long. In the first ten seconds immediately after the $S$ arrival, the amplitude decay is irregular. After this stage it can be reasonably described by straight lines. According to the single backscattering model the coda energy arriving at the same lapse time comes from an ellipsoid with the hypocenter and the station as its foci. Therefore, the coda in each window samples a volume between two ellipsoids. For a rough estimation we can consider that window 1 samples a $120 \mathrm{~km}$ wide strip of the subduction zone in the east-west direction, and window 2 samples a $240 \mathrm{~km}$ wide strip, that is, about the same dimension as the mainshock rupture zone. 
Two factors may affect $Q$ values measured from the early part of the coda (window 1). First, the early coda- $Q$ is unstable due to path and source dependence (RAUTIAN and KHALTURIN, 1978). Then, station site and near-surface effects may dominate the decay of early coda (SPUDich and Bostwick, 1987; STECK et al., 1989). The use of early coda in this study is justified by the consideration that the aim of the study is to search for earthquake-related temporal and spatial variation, disregarding the exact mechanism and absolute value of $Q$. As our result shows, the measured $Q$ is stable when averaged over many paths and the near-surface effect is significant but does not dominate.

The stability of the results was tested by using various data subsets, for example, near events, events grouped in hypocenter space, events that produced especially good seismograms. These selected data did not lead to any significant improvement in the variance, but reduced the sample number greatly. The near-surface effects contribute substantially to the early coda, especially at the low-frequencies, but they are not the only factors controlling coda decay. This is evidenced by a comparison of the measurements at the same station for different source regions. Extensive tests in this study showed that the conclusions do not depend on the particular choice of station and event grouping, window starting or ending time, or whether Aki's or Sato's model was used.

The results were also tested for possible dependence on depth or magnitude of the source, or distance. No correlations were found except a tendency for coda- $Q$ to increase slightly with depth. Any depth dependence is uncertain because of the small number of deep events.

The resulting coda- $Q$ 's show considerable variance. At low frequencies extremely high values are often measured at several nearby stations due to trapped modes or slowly decaying surface waves (PHILlIPS and AKI, 1986). These values do not reflect the attenuation and scattering property of the lithosphere. In window 2, signal-to-noise ratio is usually low in the $12 \mathrm{~Hz}$ band, especially at the western stations. Noise is an important source of errors. In order to reject the extreme values and restrain the data scatter below a reasonable level, a data acceptance criterion was set, based on the relative error $d Q / Q$ of each measurement. Table 1 shows how the mean $Q$ value, the standard deviation expressed as percentage of the mean value, and the number of accepted samples (in parentheses) are affected by different thresholds of $d Q / Q$. The data include all events east of longitude $177^{\circ} \mathrm{W}$ in the depth range $0-80 \mathrm{~km}$ and recorded by stations $\mathrm{AD} 1, \mathrm{AD} 2$, and $\mathrm{AD} 3$. It is seen that for $d Q / Q$ below $30 \%$ the sample number decreases rapidly while the standard deviation does not change significantly. In this paper we set the $d Q / Q$ threshold for data acceptance to be $40 \%$ for the $1.5 \mathrm{~Hz}$ band of window 1 and $30 \%$ for the remainder. It is considered that the results in $1.5 \mathrm{~Hz}$ band of both windows, and $12 \mathrm{~Hz}$ band of window 2 are less reliable because of the high data rejection rate and low $S / N$ ratio. 
Table I

The effect of $d Q / Q$ acceptance threshold on the average $Q_{c}$ and standard deviation. Number of samples in parentheses. Data from the stations $A D 1, A D 2, A D 3$. Events east of $177^{\circ} \mathrm{W}$ in the depth range $0-80 \mathrm{~km}$

\begin{tabular}{|c|c|c|c|c|}
\hline \multicolumn{5}{|c|}{ Window 1 (total sample number 267 ) } \\
\hline$d Q / Q$ & $1.5 \mathrm{~Hz}$ & $3.0 \mathrm{~Hz}$ & $6.0 \mathrm{~Hz}$ & $12 \mathrm{~Hz}$ \\
\hline $60 \%$ & $120 \pm 27 \%(188)$ & $238 \pm 34 \%(242)$ & $472 \pm 32 \%(267)$ & $789 \pm 27 \%(261)$ \\
\hline $40 \%$ & $101 \pm 26 \%(129)$ & $221 \pm 29 \%(214)$ & $459 \pm 27 \%(261)$ & $780 \pm 21 \%(260)$ \\
\hline $30 \%$ & $98 \pm 23 \%(124)$ & $209 \pm 20 \%(190)$ & $439 \pm 23 \%(243)$ & $776 \pm 20 \%(258)$ \\
\hline $25 \%$ & $85 \pm 19 \%(45)$ & $197 \pm 20 \%(126)$ & $427 \pm 22 \%(221)$ & $774 \pm 20 \%(256)$ \\
\hline $20 \%$ & $80 \pm 18 \%(15)$ & $187 \pm 21 \%(77)$ & $410 \pm 22 \%(173)$ & $764 \pm 19 \%(243)$ \\
\hline $15 \%$ & $65 \pm 9 \%(4)$ & $176 \pm 21 \%(21)$ & $381 \pm 20 \%(85)$ & $740 \pm 18 \%(205)$ \\
\hline \multicolumn{5}{|c|}{ Window 2 (total sample number 303 ) } \\
\hline$d Q / Q$ & $1.5 \mathrm{~Hz}$ & $3.0 \mathrm{~Hz}$ & $6.0 \mathrm{~Hz}$ & $12 \mathrm{~Hz}$ \\
\hline $60 \%$ & $206 \pm 33 \%(261)$ & $308 \pm 22 \%(303)$ & $520 \pm 20 \%(302)$ & $939 \pm 28 \%(295)$ \\
\hline $40 \%$ & $190 \pm 25 \%(234)$ & $305 \pm 19 \%(301)$ & $516 \pm 15 \%(301)$ & $928 \pm 23 \%(292)$ \\
\hline $30 \%$ & $179 \pm 21 \%(201)$ & $304 \pm 18 \%(299)$ & $515 \pm 15 \%(300)$ & $916 \pm 18 \%(286)$ \\
\hline $25 \%$ & $170 \pm 19 \%(153)$ & $303 \pm 18 \%(296)$ & $515 \pm 15 \%(299)$ & $916 \pm 18 \%(285)$ \\
\hline $20 \%$ & $157 \pm 17 \%(93)$ & $299 \pm 16 \%(285)$ & $513 \pm 14 \%(295)$ & $911 \pm 18 \%(282)$ \\
\hline $15 \%$ & $137 \pm 15 \%(28)$ & $292 \pm 16 \%(235)$ & $509 \pm 14 \%(286)$ & $901 \pm 17 \%(265)$ \\
\hline
\end{tabular}

\section{Coda- $Q$ in the Adak Seismic Zone}

The average values of coda- $Q$ measured at individual stations are listed in Table 2. The standard deviation expressed as percentage of the mean and the sample number, in parentheses, are also shown. It is found that, in spite of the large value of the standard deviation, the mean $Q$ values are near each other among properly grouped stations. In searching for spatial and temporal variations of coda- $Q$, it is desirable to use data from individual stations in order to avoid station site effects. On the other hand it is advantageous, sometimes necessary, to group several stations together, so as to effectively average out the path and source dependence.

From Table 2 we see that, in window 1, stations AD1 through AD5 show similar higher $Q$ value, while the other stations show consistently lower $Q$. In window 2 the mean $Q$ values are similar at all stations, except AD4 and AD5 that produced higher $Q$. Henceforth, the stations are usually divided into four groups. The eastern station group includes $\mathrm{AD} 1, \mathrm{AD} 2$, and $\mathrm{AD} 3$. The central group includes $\mathrm{AD} 4$ and $\mathrm{AD} 5$. The western group includes $\mathrm{AD} 6, \mathrm{AD}$, AK1, AK2, and AK3. Station ADK, a conventional observatory with three components each of long- and short-period instruments, has the largest data volume and forms a separate data group. ADK is located closest to the central stations (Figure 1), but its coda decay behavior is similar to the western stations. 
Table 2

Average coda-Q at stations of the CASN. Standard deviation is given in percent of the mean, number of samples is in parentheses

\begin{tabular}{ccccc}
\hline & \multicolumn{5}{c}{ Window } & & \\
& $1.5 \mathrm{~Hz}$ & & $3.0 \mathrm{~Hz}$ & $12 \mathrm{~Hz}$ \\
\hline AD1 & $89 \pm 24 \%(49)$ & $193 \pm 21 \%(64)$ & $428 \pm 24 \%(86)$ & $776 \pm 22 \%(90)$ \\
AD2 & $102 \pm 23 \%(64)$ & $212 \pm 21 \%(104)$ & $439 \pm 24 \%(126)$ & $755 \pm 21 \%(135)$ \\
AD3 & $98 \pm 21 \%(38)$ & $206 \pm 18 \%(57)$ & $427 \pm 23 \%(83)$ & $787 \pm 18 \%(88)$ \\
AD4 & $97 \pm 25 \%(31)$ & $214 \pm 17 \%(47)$ & $439 \pm 23 \%(68)$ & $835 \pm 21 \%(68)$ \\
AD5 & $101 \pm 20 \%(55)$ & $207 \pm 21 \%(88)$ & $413 \pm 24 \%(123)$ & $787 \pm 21 \%(115)$ \\
AD6 & $86 \pm 24 \%(27)$ & $176 \pm 26 \%(35)$ & $368 \pm 17 \%(40)$ & $685 \pm 22 \%(34)$ \\
AD7 & $82 \pm 28 \%(17)$ & $171 \pm 20 \%(33)$ & $380 \pm 25 \%(32)$ & $671 \pm 24 \%(27)$ \\
ADK & $93 \pm 23 \%(90)$ & $178 \pm 21 \%(134)$ & $384 \pm 26 \%(154)$ & $674 \pm 23 \%(116)$ \\
AK1 & $90 \pm 20 \%(60)$ & $183 \pm 21 \%(70)$ & $366 \pm 23 \%(86)$ & $678 \pm 23 \%(64)$ \\
\hline & & & \\
& & & & \\
& & $3.0 \mathrm{~Hz}$ & & \\
ADdow & & & \\
AD1 & $172 \pm 22 \%(77)$ & $289 \pm 19 \%(99)$ & $525 \pm 18 \%(97)$ & $986 \pm 20 \%(95)$ \\
AD2 & $179 \pm 20 \%(100)$ & $300 \pm 19 \%(149)$ & $494 \pm 13 \%(153)$ & $856 \pm 14 \%(149)$ \\
AD3 & $182 \pm 21 \%(60)$ & $325 \pm 17 \%(105)$ & $537 \pm 13 \%(103)$ & $949 \pm 19 \%(96)$ \\
AD4 & $191 \pm 21 \%(59)$ & $344 \pm 23 \%(88)$ & $615 \pm 20 \%(90)$ & $1028 \pm 25 \%(83)$ \\
AD5 & $199 \pm 21 \%(93)$ & $370 \pm 23 \%(128)$ & $588 \pm 19 \%(130)$ & $1109 \pm 25 \%(118)$ \\
AD6 & $155 \pm 25 \%(36)$ & $312 \pm 19 \%(46)$ & $546 \pm 19 \%(47)$ & $1090 \pm 24 \%(35)$ \\
AD7 & $156 \pm 17 \%(29)$ & $288 \pm 16 \%(38)$ & $478 \pm 17 \%(38)$ & $947 \pm 26 \%(27)$ \\
ADK & $161 \pm 24 \%(154)$ & $293 \pm 17 \%(185)$ & $516 \pm 18 \%(186)$ & $1024 \pm 23 \%(101)$ \\
AK1 & $168 \pm 21 \%(73)$ & $293 \pm 19 \%(88)$ & $504 \pm 21 \%(88)$ & $1032 \pm 25 \%(54)$ \\
\hline
\end{tabular}

\section{Spatial Distribution of Coda-Q before the Mainshock}

The $Q$ values of window 1 shown in Table 2 indicate that coda- $Q$ may differ in regions east and west of longitude $177^{\circ} \mathrm{W}$, considering that each station records more near events than distant ones. To minimize the near-station effects and highlight the differences between source regions, we compare $Q$ values determined for the same station group but different source regions.

Figure 2 shows the average coda- $Q$ values for four station groups and three event source regions. The three source regions are partitioned at longitude $177^{\circ} \mathrm{W}$ and $176^{\circ} \mathrm{W}$. The $Q$ values in the 6 and $12 \mathrm{~Hz}$ frequency bands are shown for window 1 . A coda- $Q$ increase of $10-15 \%$ from west to center source region is seen in all station groups. The difference between the center and east source regions is not so clear and consistent. In view of the $Q$ values given by those larger data sets, such as AD123 (this notation means stations AD1, AD2, and $\mathrm{AD} 3) \mathrm{AD} 45$, and $\mathrm{ADK}$ at $6 \mathrm{~Hz}$, we can say that the east region between longitudes $176^{\circ} \mathrm{W}$ and $175^{\circ} \mathrm{W}$ is also a high $Q$ region. Crossing longitude $176^{\circ} \mathrm{W}$ to the east, the eastern stations (AD123) show a slight $Q$ increase, the central stations 

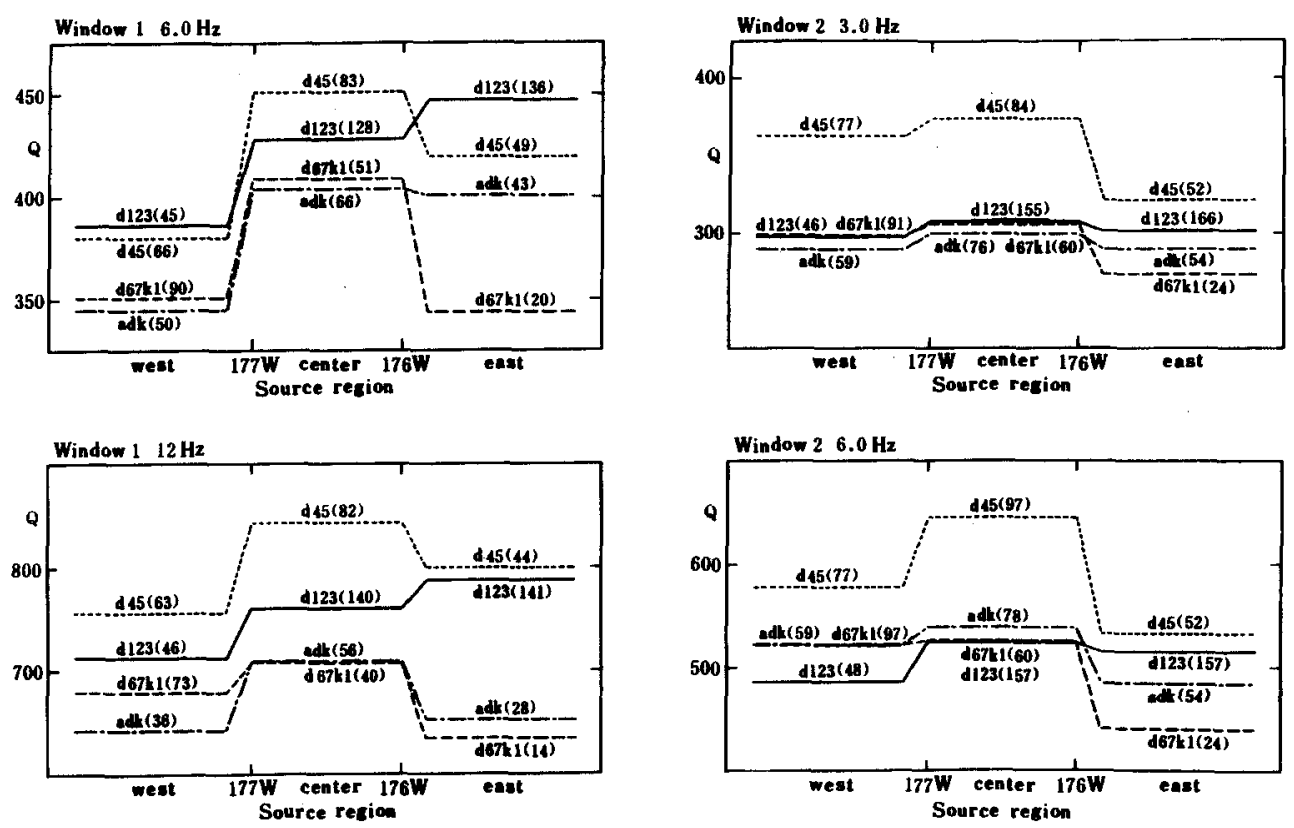

Figure 2

Coda- $Q$ measured in the two sampling windows for different station group-source region combinations. West, center, and east source regions are partitioned by longitudes $177^{\circ} \mathrm{W}$ and $176^{\circ} \mathrm{W} . \mathrm{d} 123=\mathrm{AD} 1$,

AD2, AD3; d45 = AD4, AD5; d67k1 = AD6, AD7, AK1. Number of samples in parentheses.

(AD45, ADK) show a small Q decrease, while the western stations show a larger decrease. A possible explanation for this rather systematic $Q$ change is that, with the source region fixed and the station moving to the west, the long axis of the sampled ellipsoid rotates toward the east-west direction, and thus extends more into the segments west of $177^{\circ} \mathrm{W}$ and east of $175^{\circ} \mathrm{W}$ which is probably also a low $Q$ region, as described in the following.

Because the station separation is much smaller than the sampling volume of window 2, the $Q$ difference among station groups should be small for the same source region, provided the site effect is the same for all stations. This is generally true except for station group AD45, for which the curve is well above the others, indicating a stronger positive site effect at these stations. Comparing the three source regions, the center region yields the highest $Q$ and the east region gives the lowest $Q$. The differences are not as large and clear as in window 1 , but they are quite consistent among station groups and frequency bands. The low coda- $Q$ given by east region events is difficult to interpret if we assume that the whole rupture zone has the same high $Q$ value. Because in this case the sampling volume of window 2, which is about as wide as the rupture zone, would have contained the largest proportion of high $Q$ medium, thus would have produced the highest 
coda- $Q$ for the east source region. It is therefore inferred that the region east of the mainshock epicenter is probably of low $Q$.

Synthesizing the results from both sampling windows, we find that the coda- $Q$ in the region between longitudes $177^{\circ} \mathrm{W}$ to $175^{\circ} \mathrm{W}$ is $15 \%$ higher than that in the region west of longitude $177^{\circ} \mathrm{W}$. To the east of the mainshock epicenter coda- $Q$ may decrease quite rapidly, giving rise to a discernible difference in window 2 measurements. Due to lack of data in the eastern side of the study area, the low $Q$ in the east cannot be confirmed by window 1 measurements.

\section{Temporal Variation of Coda- $Q$ before the Mainshock}

A thorough search was made for precursory-like changes in coda- $Q$ in various station-source region combinations. We found only more-or-less random fluctuations within an amplitude range which depended on the size of data set and the length of the averaging time window. Figure 3 shows three examples of temporal coda- $Q$ change measured in sampling window 1: (a) stations AD7, ADK, and AK1, events west of $176.5^{\circ} \mathrm{W}$, (b) stations $\mathrm{AD} 1, \mathrm{AD} 2, \mathrm{AD} 3, \mathrm{AD} 4$, and $\mathrm{AD} 5$, events between $176^{\circ} \mathrm{W}$ and $177^{\circ} \mathrm{W}$, (c) same stations as in (b), events east of $176^{\circ} \mathrm{W}$. Coda- $Q$ values are expressed as the percent departure from the overall mean (averaged over the whole time period) of each frequency band. The curves show the coda- $Q$ averaged over a one-year window with six-month overlap. The standard deviations in each window are not shown in the figures, but they are generally in the 20 to 25 percent range. Some curves may appear biased to one side of the mean, because the sample numbers in each window are not equal. The total sample numbers in each band are given in the legend at the upper right corner. For window 2, bottom panel stations AD1, AD2, AD3, AD7, ADK, and AK1 and all events are utilized. From these figures we can see that one-year average coda varies within a range of about $10 \%$ around the mean value. We can neither define a stable normal base value, nor find any consistent pattern that might be interpreted as a precusor to the mainshock. It is deduced that if a precursory $Q$ change occurred, its magnitude is below $10 \%$ or its duration is shorter than one year, so that it could not be resolved from our data set.

The pre-mainshock period (Jan. 1981-Apr. 1986) was divided into an earlier and a later period. The average $Q$ values in these two periods were compared to find whether any systematic change existed. Table 3 gives a typical result which compares the coda- $Q$ change before and after June 1983. Shown in the table are $Q$ increase (with plus sign) or decrease (with minus sign) in percentage of the earlier period value. It can be seen that the percent changes are generally small and inconsistent among stations and frequency bands. An exception is the large $Q$ increase in the $12 \mathrm{~Hz}$ band of window 2. It is more prominent at stations AD7, $\mathrm{ADK}$, and AK1, where $S / N$ ratio is very low, but is totally absent in the $6 \mathrm{~Hz}$ band of the same sampling window. After the mainshock, coda- $Q$ did not change 

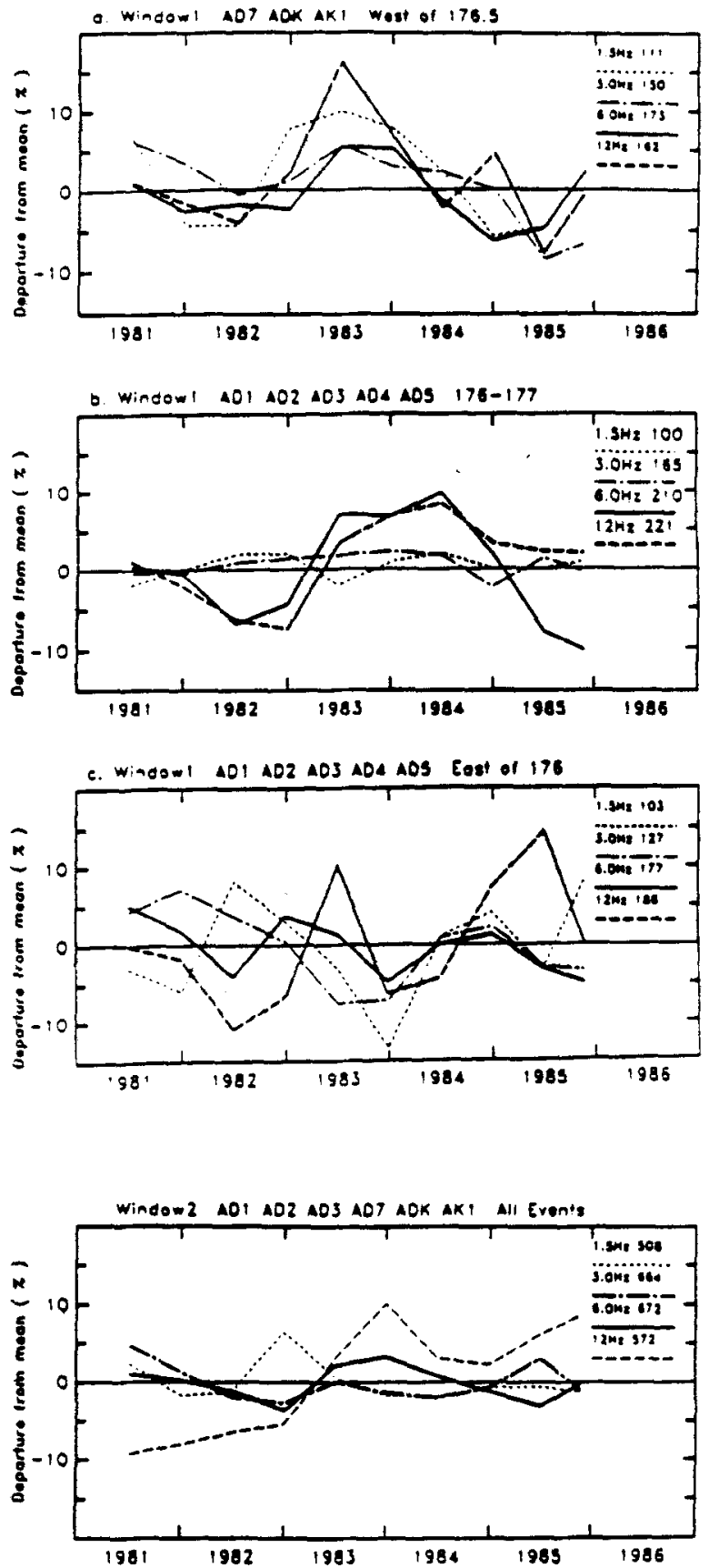

Figure 3

Temporal variation of coda- $Q$ prior to the mainshock. The one-year average value, expressed as the percent departure from the mean for the whole time period, is plotted for each frequency band. In the top three panels the numbers following the frequency in the upper right corner show the total sample number in that band in window 1. Recording stations and event source region are shown on top of each panel. 
Table 3

Differences in coda- $Q$ during the intervals Jan. 1981 to Jun. 83 and Jul. 1983 to Apr. 1986. Differences are expressed as the percentage of the first-period value. Plus sign indicates $Q_{c}$ increase. Cases with fewer than 10 samples in either interval were discarded

\begin{tabular}{|c|c|c|c|c|c|c|c|c|}
\hline & AD1 & AD2 & AD3 & $\begin{array}{l}\text { Window } 1 \\
\text { AD4 }\end{array}$ & AD5 & $\mathrm{AD} 7$ & ADK & AK1 \\
\hline $1.5 \mathrm{~Hz}$ & - & $+8 \%$ & $-3 \%$ & - & $+2 \%$ & - & $-5 \%$ & $-4 \%$ \\
\hline $3.0 \mathrm{~Hz}$ & $0 \%$ & $-5 \%$ & $+2 \%$ & $-7 \%$ & $-6 \%$ & $-18 \%$ & $-9 \%$ & $+5 \%$ \\
\hline $6.0 \mathrm{~Hz}$ & $+1 \%$ & $+3 \%$ & $-8 \%$ & $0 \%$ & $-9 \%$ & $+5 \%$ & $-8 \%$ & $+2 \%$ \\
\hline \multirow[t]{2}{*}{$12 \mathrm{~Hz}$} & $+7 \%$ & $+5 \%$ & $+5 \%$ & $+4 \%$ & $0 \%$ & $-1 \%$ & $-3 \%$ & $+8 \%$ \\
\hline & AD1 & AD2 & AD3 & $\begin{array}{l}\text { Window } 2 \\
\text { AD4 }\end{array}$ & AD5 & AD7 & ADK & AK1 \\
\hline $1.5 \mathrm{~Hz}$ & $-4 \%$ & $-2 \%$ & $+2 \%$ & $+3 \%$ & $-1 \%$ & $-7 \%$ & $-3 \%$ & $+1 \%$ \\
\hline $3.0 \mathrm{~Hz}$ & $+1 \%$ & $-6 \%$ & $+2 \%$ & $0 \%$ & $+1 \%$ & $-5 \%$ & $-1 \%$ & $-1 \%$ \\
\hline $6.0 \mathrm{~Hz}$ & $+2 \%$ & $-1 \%$ & $0 \%$ & $+1 \%$ & $-3 \%$ & $+6 \%$ & $-5 \%$ & $+9 \%$ \\
\hline $12 \mathrm{~Hz}$ & $+12 \%$ & $+2 \%$ & $+13 \%$ & $+19 \%$ & $+11 \%$ & $+23 \%$ & $+22 \%$ & $+19 \%$ \\
\hline
\end{tabular}

significantly in the $12 \mathrm{~Hz}$ band of window 2 (Figures 4,5). On the other hand, viewed in sampling window 1, the spatial difference and the coseismic change are shown in all frequency bands, indicating that the $12 \mathrm{~Hz}$ band does not behave uniquely. Therefore, the pre-mainshock $Q$ increase in $12 \mathrm{~Hz}$ band of window 2 is probably not related to tectonic causes.

\section{Coda-Q after the Mainshock}

Forty aftershocks in June and July, 1986, between $175^{\circ} \mathrm{W}$ and $177^{\circ} \mathrm{W}$, were selected for this part of the study, which was intended to look for attenuation changes that could be reasonably interpreted as coseismic. For these events, stations AD1, AD2, AD3, and ADK provided good data, allowing us to study the coseismic $Q$ change in the main shock source region. The events were too small to be recorded by the western stations, and so few events occurred west of the aftershock zone during this time interval that is was not possible to examine coda- $Q$ outside the rupture zone.

Table 4 lists the average $Q$ values from preshocks (Jan. 1981-Apr. 1986) and aftershocks east of $177^{\circ} \mathrm{W}$. In this study the statistical significances were determined from the standard $z$-parameter for testing the significance of the difference of two mean values, using the probability table for normal distributions. For the stations other than ADK, the confidence levels on the significance of the differences are $99.9 \%$ in the 3 and $6 \mathrm{~Hz}$ bands, and $99 \%$ in the 1.5 and $12 \mathrm{~Hz}$ bands. For ADK, 
Table 4

Coda- $Q$ before and after the 1986 mainshock. Parentheses indicate that the statistical significance of the difference is below 99\%

\begin{tabular}{|c|c|c|c|c|c|c|c|c|c|}
\hline \multirow[b]{2}{*}{ Stations } & \multirow[b]{2}{*}{$Q$} & \multicolumn{4}{|c|}{ Window 1} & \multicolumn{4}{|c|}{ Window 2} \\
\hline & & $1.5 \mathrm{~Hz}$ & $3.0 \mathrm{~Hz}$ & $6.0 \mathrm{~Hz}$ & $12 \mathrm{~Hz}$ & $1.5 \mathrm{~Hz}$ & $3.0 \mathrm{~Hz}$ & $6.0 \mathrm{~Hz}$ & $12 \mathrm{~Hz}$ \\
\hline $\mathrm{AD} 1, \mathrm{AD} 2$ & $Q_{\text {pre }}$ & 100 & 210 & 443 & 776 & 179 & 309 & 529 & 928 \\
\hline AD3 & $\begin{array}{l}Q_{\text {after }} \\
Q_{\text {decrease }}\end{array}$ & $\begin{array}{r}87 \\
13 \%\end{array}$ & $\begin{array}{c}187 \\
11 \%\end{array}$ & $\begin{array}{c}396 \\
11 \%\end{array}$ & $\begin{array}{l}728 \\
6 \%\end{array}$ & $\begin{array}{c}176 \\
(2 \%)\end{array}$ & $\begin{array}{c}292 \\
(6 \%)\end{array}$ & $\begin{array}{c}509 \\
(4 \%)\end{array}$ & $\begin{array}{c}937 \\
(-1 \%)\end{array}$ \\
\hline ADK & $\begin{array}{l}Q_{\text {pre }} \\
Q_{\text {after }} \\
Q_{\text {decrease }}\end{array}$ & $\begin{array}{c}96 \\
89 \\
(7 \%)\end{array}$ & $\begin{array}{c}179 \\
169 \\
(6 \%)\end{array}$ & $\begin{array}{c}404 \\
362 \\
10 \%\end{array}$ & $\begin{array}{c}690 \\
613 \\
11 \%\end{array}$ & $\begin{array}{c}166 \\
176 \\
(-6 \%)\end{array}$ & $\begin{array}{c}296 \\
282 \\
(5 \%)\end{array}$ & $\begin{array}{c}517 \\
484 \\
(6 \%)\end{array}$ & $\begin{array}{c}1000 \\
1069 \\
(-7 \%)\end{array}$ \\
\hline
\end{tabular}

the $10 \%$ decrease is significant at the $99 \%$ confidence level. Parentheses indicate that the statistical significance of the change is below $99 \%$. From the table we can see that coda- $Q$ decreased about $10 \%$ within the part of the mainshock rupture zone sampled by these data.

The post-event $Q$ value is displayed, together with the temporal variation before the mainshock, in Figures 4 and 5. The curves show $Q$ values averaged over a sample number equal to the aftershock sample number in the corresponding frequency band. In sampling window 1, the pre-mainshock $Q$ varied within a narrow range (about $5 \%$ around the mean value at stations $A D 1, A D 2$, and AD3, Figure 4), and was not correlated between frequency bands. The postmainshock $Q$ dropped clearly below the pre-event fluctuation range in the $1.5,3,6 \mathrm{~Hz}$ bands at these stations, and in the $6 \mathrm{~Hz}$ band at ADK. The $Q$ changes in the other bands, window 1 , are not highly significant, but do not contradict the evidence for a coseismic $Q$ decrease. In sampling window 2, the coseismic change was insignificant. From the above evidence, a coseismic $Q$ decrease of about 10 percent in the rupture zone can be accepted with reasonable confidence. The long-term post-event behavior of $\operatorname{coda}-Q$ is the subject for a separate study.

\section{Summary and Conclusions}

Coda- $Q$ values in segments of the seismogenic zone before and after the 1986 Andreanof Islands earthquake in the central Aleutian subduction zone have been measured on the basis of Aki's single backscattering model. The main findings in this study can be summarized as follows. 

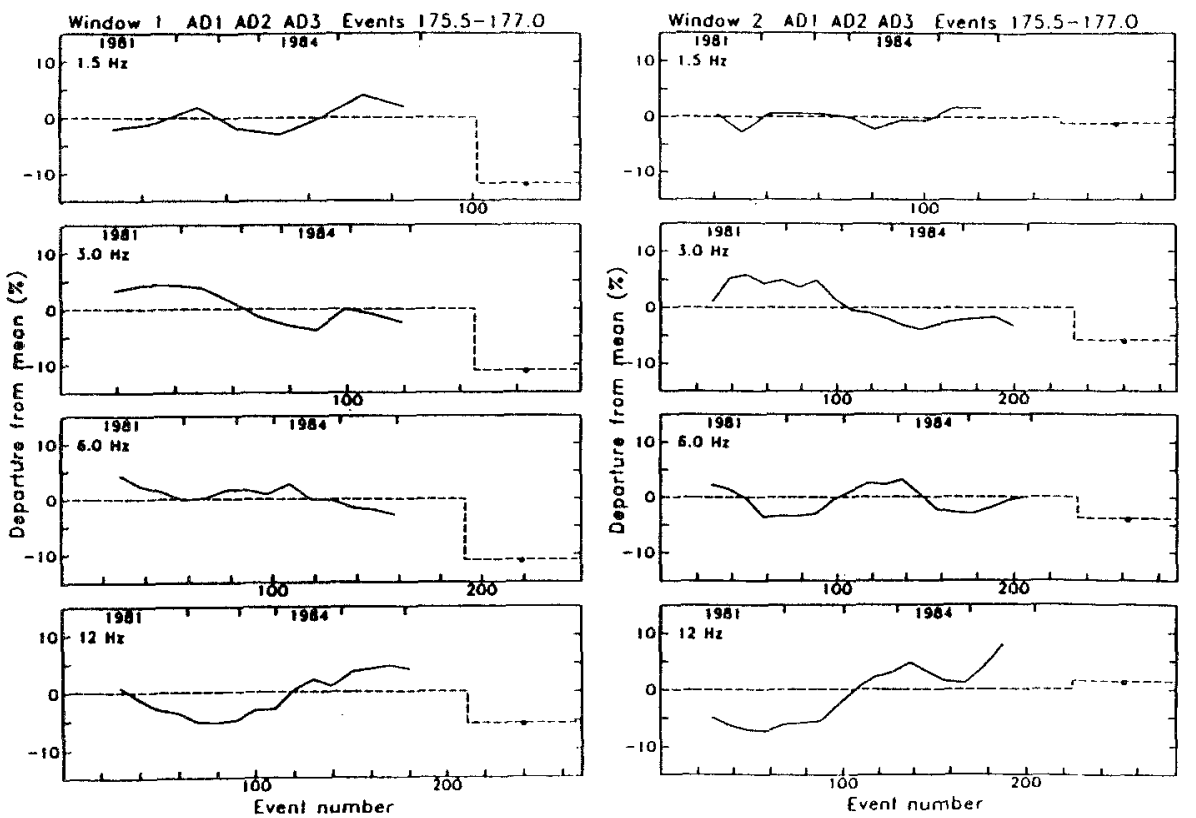

Figure 4

Coda- $Q$ before and after the 1986 mainshock from stations AD1, AD2, AD3 and events between $175.5^{\circ} \mathrm{W}$ and $177^{\circ} \mathrm{W}$. Left : sampling window 1. Right: window 2 . The broken line shows the pre- and after-mainshock mean value. The solid curve is the sliding average for preshock events over a sample number equal to the aftershock number. All $Q$ values are expressed as the percent departure from the preshock mean.

Before the mainshock, coda- $Q$ in the rupture zone west of the mainshock epicenter was $15 \%$ higher than that in the region west of the rupture zone. A lower $Q$ in the region east of the mainshock epicenter is inferred, but solid evidence is lacking because of the areal coverage provided by the local network. After the mainshock, coda- $Q$ within the rupture zone decreased about $10 \%$

$Q$ changes that might have been precursors were not found in the 5.4 years preceding the mainshock. It is deduced that a coda- $Q$ anomaly, if it existed, was of small magnitude $(<10 \%)$, or its duration was either shorter than one year or longer than four years.

The coda- $Q$ difference between regions west and east of longitude $177^{\circ} \mathrm{W}$ could be a stress-induced feature associated with the mainshock, based on several lines of evidence. First, the boundary of $Q$ provinces coincides with the western limit of the aftershock zone. Secondly, coda- $Q$ decreased about $10 \%$ within the rupture zone, which accounted for most of the pre-mainshock spatial difference. Finally the inferred low $Q$ in a region east of the mainshock epicenter could be explained by the fact that the moment release in this part of rupture zone was smaller (HwANG and Kanamori, 1986; DAS and Kostrov, 1990). 

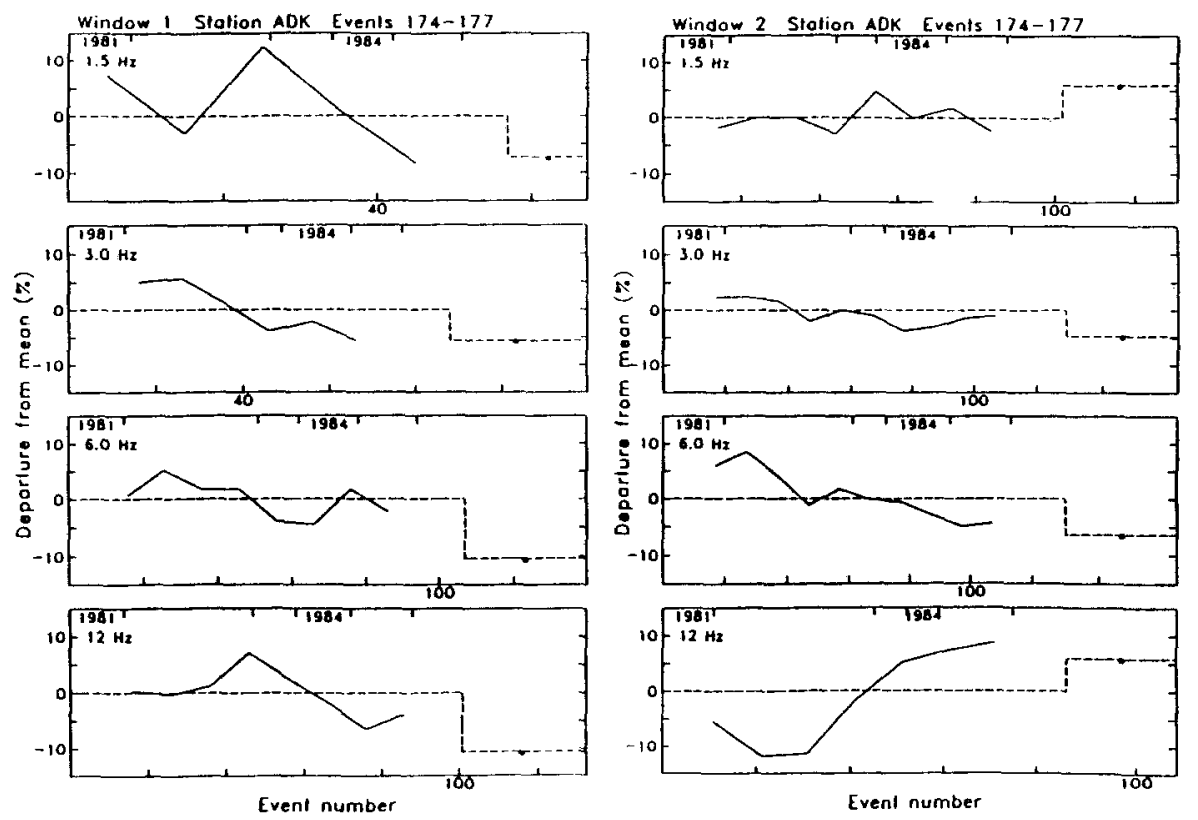

Figure 5

Coda- $Q$ before and after the 1986 mainshock from station ADK and events east of longitude $177^{\circ} \mathrm{W}$. Notation the same as for Figure 4.

The coseismic $Q$ decrease found in this study must be considered tentative, as it is based on a rather small number of well-recorded aftershocks. This result agrees with PENG et al. (1986), but contradicts other reports of a coseismic $Q$ increase (e.g., SU and AKI, 1990). Our result seems to contradict in several aspects the hypothesis that dilatant microcrack formation is an important factor affecting the temporal change of $Q$. That hypothesis predicts an accelerating $Q$ decrease before and a $Q$ increase after an earthquake, with high frequency waves being more affected. It may be easier to relate our findings to the loading process of a volume surrounding a locked fault patch, i.e, a very slow increase and a sudden release of compression that affect cracks of all scales.

The path and source dependence is an important factor affecting coda- $Q$ measurements in our study, in which small differences in $Q$ are involved. Spatial variation and site effects add to the difficulty in searching for precursory changes. When the data set is reduced to small size, the result is usually unstable and inconsistent. In recent years HUANG and WYSS (1988) and GoT et al. (1990) reported that temporal coda- $Q$ changes were small and indiscernible in two cases. Nevertheless the spatial distribution and coseismic change of coda- $Q$ found so far could shed light on the physics in an earthquake source region. 


\section{Acknowledgement}

We thank M. Wyss, F. Scherbaum, S. Billington and two anonymous reviewers for helpful discussions and comments on the paper. We are grateful to everyone working in the Adak Project group who made the data available. This work was supported by U.S. Geological Survey Grant No. 14-08-0001-G1099.

\section{REFERENCES}

AKI, K. (1985), Theory of Earthquake Prediction with Special' Reference to Monitoring of the Quality Factor of Lithosphere by the Coda Method, Earthq. Predict. Res. 3, 219-230.

AKI, K., and CHouet, B. (1975), Origin of Coda Waves: Source, Attenuation and Scattering Effects, J. Geophys. Res. 80, 3322-3342.

Boyd, T. M., and NABelek, J. L. (1988), Rupture Process of the Andreanof Islands Earthquake of May 7, 1986, Bull. Seismol. Soc. Am. 78, 1653-1673.

DAs, S., and Kostrov, B. V. (1990), Inversion for Seismic Slip Rate History and Distribution with Stabilizing Constraints: Application to the 1986 Andreanof Islands Earthquake, J. Geophys. Res. 95 , $6899-6913$.

Engdahl, E. R., Billington, S., and Kisslinger, C. (1989), Teleseismically Recorded Seismicity before and after the May 7, 1986, Andreanof Islands, Alaska, Earthquake, J. Geophys. Res. 94, $15,481-15,498$.

Got, J. L., Poupinet, G., and FrÉchet, I. (1990), Changes in Source and Site Effects Compared to Coda $Q^{-1}$ Temporal Variations Using Microearthquake Doublets in California, Pure Appl. Geophys. $134,195-228$.

Gusev, A. A., and Lemzikov, V. K. (1985), Properties of Scattered Elastic Waves in the Lithosphere of Kamchatka: Parameters and Temporal Variations, Tectonophys. 112, 137-153.

Houston, H., and Engdahl, E. R. (1989), A Comparison of the Spatio-temporal Distribution of Moment Release of the 1986 Andreanof Islands Earthquake with Relocated Seismicity, Geophys. Res. Lett. $16,1421-1424$.

HuANG, Z. X., and WySs, M. (1988), Coda $Q$ before the 1983 Hawaii $\left(M_{s}=6.6\right)$ Earthquake, Bull. Seismol. Soc. Am. 78, 1279-1296.

Hwang, L. J., and Kanamori, H. (1986), Source Parameters of the May 7, 1986 Andreanof Islands Earthquake, Geophys. Res. Lett. 13, 1426-1429.

JIN, A., and AKI, K. (1986), Temporal Change in Coda $Q$ before the Tangshan Earthquake of 1976 and the Haicheng Earthquake of 1975, J. Geophys. Res. 91, 665-673.

KissLINGER, C. (1988), An Experiment in Earthquake Prediction and the May 7, 1986 Andreanof Islands Earthquake, Bull. Seismol. Soc. Am. 78, 218-229.

LaForge, R., and Engdahl, E. R. (1979), Tectonic Implications of Seismicity in the Adak Canyon Region, Central Aleutians, Bull. Seismol. Soc. Am. 69, 1515-1532.

Novelo-Casanova, D. A., Berg, E., Hsu, V., and Helsley, C. E. (1985), Time-space Variation of Seismic S-wave Coda Attenuation and Magnitude Distribution (b-values) for the Petatlan Earthquake, Geophys. Res. Lett. 12, 789-792.

Peng, J. Y., Aki, K., Chouet, B., Johnson, P., Lee, W. H. K., MArks, S., Newberry, J. T., Ryall, A. S., Stewart, S. W., and Tottingham, D. M. (1987), Temporal Changes in Coda $Q$ Associated with the Round Valley, California, Earthquake of November 23, 1984, J. Geophys. Res. 92, $3507-3526$.

PHillips, W. S., and AKI, K. (1986), Site Amplification of Coda Waves from Local Earthquakes in Central California, Bull. Seismol. Soc. Am. 76, 627-648.

Rautian, T. G., and KHAlfurin, V. I. (1978), The Use of the Coda for Determination of the Earthquake Source Spectrum, Bull. Seismol. Soc. Am. 68, 923-948. 
SATO, H. (1988), Temporal Change in Scattering and Attenuation Associated with the Earthquake Occurrence-A Review of Recent Studies on Coda Waves, Pure Appl. Geophys. 126, 465-497.

Spudich, P., and Bostwick, T. (1987), Studies of the Seismic Coda Using Earthquake Clusters as Deeply Buried Seismograph Arrays, J. Geophys. Res. 92, 10,526-10,546.

Steck, L. K., Prothero, W. A., and Scheimer, J. (1989), Site-dependent Coda $Q$ at Mono Craters, California, Bull. Seismol. Soc. Am. 79, 1559-1574.

Su, F., and AKı, K. (1990), Temporal and Spatial Variation on Coda $Q^{-1}$ Associated with the North Palm Springs Earthquake of July 8, 1986, Pure Appl. Geophys. 133, 23-52.

Tsukuda, T. (1988), Coda $Q$ before and after the 1983 Misasa Earthquake of M6.2, Tottori Prefecture, Japan, Pure Appl. Geophys. 128, 261-279.

(Received June 13, 1991, revised December 20, 1991, accepted January 4, 1992) 